\title{
Research Output and Economic Growth in G7 Countries: New Evidence from Asymmetric Panel Causality Testing
}

\author{
Abdulnasser Hatemi-J*, Ahdi N. Ajmi*, Ghassen El Montasser`, Roula Inglesi-Lotz^ and \\ Rangan Gupta`
}

\begin{abstract}
Recent studies have shown increasing interest on the relationship between research output and economic growth. The study of such a relationship is not only of theoretical interest, but it can also influence specific policies to improve the quality, and probably the quantity of research output. This paper has studied this relationship in G7 countries using the asymmetric panel causality test of Hatemi-J (2011). Our results show that only the United Kingdom shows a causal relationship from the output of research to real GDP. However, when the signs of variations are taken into account, there is an asymmetric causality running from negative research output shocks to negative real GDP shocks.
\end{abstract}

JEL Classification: C33, O3, O4

Keywords: Research Output, Real GDP, Asymmetric Panel Causality, G7

\section{Introduction}

The traditional factors of production include capital, labour and technological progress. But what is the glue that connects and improves all of them? The endogenous growth theory promotes that investment in human capital, innovation and knowledge will have the desirable positive effects on economic growth both at a macro and micro level. Romer (1986) supported the fact that knowledge externalities can improve all factors of production and hence the productive

\footnotetext{
*Department of Economics and Finance, Faculty of Business and Economics, United Arab Emirates University, AlAin, United Arab Emirates.

* College of Sciences and Humanities in Slayel, Salman bin Abdulaziz University, Kingdom of Saudi Arabia.

- Ecole supérieure de commerce de Tunis, University of Manouba, Tunisia.

^ Corresponding author. Department of Economics, University of Pretoria, Pretoria, 0002, South Africa. Email: roula.inglesi-lotz.up.ac.za.

• Department of Economics, University of Pretoria, Pretoria, 0002, South Africa.
} 
capabilities of the countries. Knowledge can be materialized in books, research publications or it can also be more abstract presented through better physical or human capital. Lucas (1988) discussed extensively the significance of knowledge as improved human capital. As Inglesi-Lotz and Pouris (2013) mention, higher education, training on specific skills and life education can advance the quality of human capital within a country but also worldwide.

Academic research embodies both forms of accumulated knowledge: through books and research publications and through improved human capital quality. Involvement in research activities, reading the existing literature, learning new methods can all result in the production of research output. At the same time, the academics improve their quality and quantity of knowledge that can be transmitted to the students. To proxy the human capital, various studies used indicators such as the total secondary school enrolments in a country or input indicators such as the Research and Development (R\&D) expenditures (Fedderke and Schirmer, 2006). However, counting the research output expressed in academic papers or books is a more quantifiable and straightforward variable to measure the stock of knowledge of a country (Inglesi-Lotz and Pouris, 2013; De Moya-Anego and Herrero-Solana 1999; King 2004). Hence, the literature has shown its preference to bibliometric and scientometric indicators. These indicators of measuring innovation through measuring research performance are among the most objective and straightforward (Pouris and Pouris, 2009). Also Price (1978) argues that "for those who are working at the research front, publication is not just an indicator but in, a very strong sense, the end product of their creative effort', Their objectivity also assists in comparative exercises or panel data applications (Schumbert and Telcs, 1986), investigating various countries' overall performance or that of specific fields of research.

The question is whether and how the research output as an expression of accumulated knowledge has a relationship with the economic growth and development of various countries. In the empirical literature, a number of studies (Price 1978; Kealey 1996; De Moya-Anego and Herrero-Solana 1999; King 2004; Fedderke and Schirmer 2006; Lee et al. 2011; Shelton and Leydersdorff 2011; Inglesi-Lotz and Pouris 2013; Inglesi-Lotz et al.; 2014; Ntuli et al. 2015; Inglesi-Lotz et al., 2015; Vinkler 2008) have investigated this question concluding that there is certainly some relationship but without any overall consensus on the direction and magnitude of 
the causality. Lee et al. (2001) have suggested that the developmental stage of the countries is a crucial factor of the relationship's strength and direction.

Moreover, there was no separation of the effect of positive shocks in the relationship from the negative ones, assuming symmetry in the results. In this paper, we examine this relationship between academic research production and economic growth for the G7 countries by allowing for asymmetry in the investigation. The impact of a negative shock in the research output of a country might be different than the impact of a positive research shock even if the size of the shock is exactly the same in absolute terms. To do so, we employ a relatively recently proposed asymmetric causality test in a panel data framework by Hatemi-J (2011, 2014). This methodology supports the notion that economic agents react differently to a negative shock than a positive one (Hatemi-J, 2011). We construct, hence, cumulative sums of positive and negative shocks in order to allow for potential asymmetric causal impact within a panel system consisting of the G7 countries. This approach also allows us to accommodate for possible instability in the causal relationships between the variables of concern, which may arise out of structural breaks (Inglesi-Lotz et al., 2014). The reason for choosing these seven countries is the fact these countries account for nearly 75 percent (73.46 percent to be precise, on average, over our period of concern: 1981-2012, with the US accounting for 35.29 percent) of total research output of the world. The rest of the paper is structured as follows. The next section discusses the recent literature on the relationship between economic growth and research productivity. Next, the methodology, as well as the data employed are presented. Finally, the empirical results are discussed followed by the conclusions and policy implications of the findings.

\section{Literature review}

In recent years, a great interest for the relationship between research output and economic growth have been expressed in the literature (Price 1978; Kealey 1996; De Moya-Anego and Herrero-Solana 1999; King 2004; Fedderke and Schirmer 2006; Lee et al. 2011; Shelton and Leydersdorff 2011; Inglesi-Lotz and Pouris 2013; Inglesi-Lotz et al.; 2014; Ntuli et al., 2015; Inglesi-Lotz et al., forthcoming; Vinkler 2008). Although the literature has not reached a certain consensus on the nature of the relationship, the majority of the studies have confirmed that there 
is some (limited or extensive) correlation between the research performance of a country (or a group of countries) measured primarily with scientometric indicators and economic growth and development (Gross Domestic Product (GDP)).

There are four possible directions of the causal relationship identified in the literature. Firstly, economic growth (GDP) might be a factor in changing the research performance of a country. Higher levels of economic growth in a country can stimulate higher knowledge capacities and a better quality of human capital that may lead to more research output. Secondly, research output and accumulated knowledge may be the drivers to increasing economic growth and development, as promoted by the endogenous growth theory. Thirdly there might be a bidirectional causality where economic growth and research output mutually affect each other or finally there might be no relationship between the two variables.

In their comprehensive books, both Price (1978) and Kealey (1996) argue the existence of a linear correlation between GDP and various scientometric variables for many countries without concluding a specific direction. For 19 Latin American countries, De Moya- Anegon and Herrero- Solana (1999) concluded that there is a significant relationship between GDP and then number of published papers in journals indexed by the Institute for Scientific Information (ISI). In the study of the OECD countries by King (2004), an exponential positive relationship was found between research articles and the countries' economic performance.

Vinkler (2008) added more heterogeneous countries to the studied mix by including Central and Eastern European countries, the overall European Union member states, the US, and Japan. He used two different scientometric indicators: the ratio of a country's papers to the overall global output and their relative impact of several fields. His conclusion was that the relationship holds for the "stronger" EU members, the US and the Japan. These results do not coincide with those by Lee et al. (2011), that in a time-series analysis, found that a mutual relationship between GDP and research output exist primarily in the developing Asian countries of the studied group but not in the developed Western countries. However, the paper attracted criticism for its econometric method by Inglesi-Lotz et al. (2014): “...the results are likely to suffer from small-sample bias due to the small number of available degrees of freedom, unless some bootstrapping procedures were used to obtain critical values for the tests." 
In order to avoid a number of problems appearing from single-country analysis and time series analysis such as not taking into account cross-sectional dependency and heterogeneity, a number of papers focused on groups of countries such as BRICS (Inglesi-Lotz et al. (forthcoming (a)) and OECD countries (Ntuli et al. 2015) in a panel data framework. Inglesi-Lotz et al. (forthcoming) concluded that in the period from 1981 to 2011, there was no causality between research performance (proxied as the percentage share of a country's academic papers to the world) and economic growth for any of the BRICS countries with the exception of India, for which the feedback hypothesis is confirmed (bidirectional causality). These results are in contrast with what Inglesi-Lotz and Pouris (2013) found for South Africa in a time-series analysis for the period 1980 to 2008 that research output influenced the increasing trend of academic publications as a share to the rest of the world. The reasons for the difference are discussed in Inglesi-Lotz et al. (forthcoming) and have to do primarily with the econometric techniques as well as the sample period.

Ntuli et al. (2015) focused on 34 OECD countries and concluded that there is a unidirectional causality running from research output (total number of academic papers published) to economic growth for the US, Finland, Hungary and Mexico; from economic growth to research performance for Canada, France, Italy, New Zealand, UK, Austria, Israel and Poland while no causality was found for the rest of the OECD countries.

Taking into account possible fluctuations in the existence and direction of the causality through the years, Inglesi-Lotz et al. (2014) have examined the relationship between knowledge (expressed in the share of the country's research output to the world) and economic growth for US for the period 1981 to 2011 . Their results confirm that the relationship does not stay constant over time: for the majority of the sample period, there was no relationship between the two variables; during the sub-periods 2003-2005 and 2009, GDP caused research output while in 2010, the opposite direction of the causality held.

In this paper, we will take the analysis a step further by looking at the possible asymmetric reactions of the system for the G7 countries. The impact of a negative shock in the research output of a country might be different than the impact of a positive research shock even if the size of the shock is exactly the same in absolute terms. 


\section{Methodology and data}

The well-known concept of causality in Granger's sense relies on the notion of whether or not the past values of one variable can increase the precession of the forecast of another one. This is commonly investigated via null hypothesis defined as zero restrictions on relevant parameters within an autoregressive regression. In case the underlying null hypothesis is rejected, it can be interpreted as empirical support for Granger causality. One issue that has been neglected within this context is allowing for potential asymmetric causal impacts. To overcome this shortcoming Hatemi-J (2011) suggest the following test. Let $x_{1}$ signify a measure of research output and let $x_{2}$ represents a measure of economic performance. These two variables are integrated of the first degree. Thus, each variable can be expressed as the following:

$$
\begin{aligned}
& x_{i 1, t}=x_{i 1, t-1}+e_{i 1, t}=x_{i 1,0}+\sum_{j=1}^{t} e_{i 1, j} \\
& x_{i 2, t}=x_{i 2, t-1}+e_{i 2, t}=x_{i 2,0}+\sum_{j=1}^{t} e_{i 2, j}
\end{aligned}
$$

For $i=1, \ldots, 7$. Where 7 is the cross-sectional dimension (as we look at the $\mathrm{G} 7$ countries) and $e_{i}$ is the error term, which is assumed to be a white noise process in each case. The positive and negative shocks are identified as $e_{i 1, t}^{+}:=\max \left(e_{i 1, t}, 0\right), e_{i 2, t}^{+}:=\max \left(e_{i 2, t}, 0\right), e_{i 1, t}^{-}:=$ $\min \left(e_{i 1, t}, 0\right)$ and $e_{i 2, t}^{-}:=\min \left(e_{i 2, t}, 0\right)$. These values can be used in order to construct the cumulative component as

$$
\begin{aligned}
& x_{i 1, t}^{+}=x_{i 1,0}^{+}+e_{i 1, t}^{+}=x_{i 1,0}+\sum_{j=1}^{t} e_{i 1, j}^{+} \\
& x_{i 2, t}^{+}=x_{i 2,0}^{+}+e_{i 2, t}^{+}=x_{i 2,0}+\sum_{j=1}^{t} e_{i 2, j}^{+} \\
& x_{i 1, t}^{-}=x_{i 1,0}^{-}+e_{i 1, t}^{-}=x_{i 1,0}+\sum_{j=1}^{t} e_{i 1, j}^{-} \\
& x_{i 2, t}^{-}=x_{i 2,0}^{-}+e_{i 2, t}^{-}=x_{i 2,0}+\sum_{j=1}^{t} e_{i 2, j}^{-}
\end{aligned}
$$


After transforming the data a vector autoregressive seemingly unrelated regression model of order $p, \operatorname{VAR}-\operatorname{SUR}(p)$, can be estimated in order to test the null hypothesis of no asymmetric causality within the panel model. It should be mentioned that this VAR-SUR $(p)$ model takes into account that the error terms across the cross-sectional units might be dependent. In case tests for causality between cumulative negative shocks of the underlying variables is conducted the vector of interest is $\left(x_{i 1, t}^{-}, x_{i 2, t}^{-}\right)$and the following $\operatorname{VAR}-\operatorname{SUR}(p)$ model is to be estimated:

$$
\left[\begin{array}{l}
x_{i 1, t}^{-} \\
x_{i 2, t}^{-}
\end{array}\right]=\left[\begin{array}{l}
\beta_{i 0} \\
\gamma_{i 0}
\end{array}\right]+\left[\begin{array}{ll}
\sum_{r=1}^{k} \beta_{i 1, r} & \sum_{r=1}^{k} \beta_{i 2, r} \\
\sum_{r=1}^{k} \gamma_{i 1, r} & \sum_{r=1}^{k} \gamma_{i 2, r}
\end{array}\right] \times\left[\begin{array}{l}
x_{i 1, t-r}^{-} \\
x_{i 2, t-r}^{-}
\end{array}\right]+\left[\begin{array}{l}
\varepsilon_{i 1}^{-} \\
\varepsilon_{i 2}^{-}
\end{array}\right]
$$

The lag order $p$ can be selected via the minimization of an information criterion. The null hypothesis that $\bar{x}_{i 2, t}^{-}$does not cause $x_{i 1, t}^{-}$for the cross-sectional unit $i$ in the panel is formulated as the following:

$$
H_{0}: \beta_{i 2, r}=0, \forall r \text {. Where } r=1, \ldots, p \text {. }
$$

This null hypothesis can be tested by via a Wald test as suggested by Hatemi-J (2011). It is also possible to test for causality between positive components $\left(x_{i 1, t}^{+}, x_{i 2, t}^{+}\right)$, in a similar way.

The annual data used in this study covers the period from 1981 to 2012 for the G7 countries (Canada, France, Germany, Italy, Japan, UK and US), with the start and end points of the sample being purely driven by data availability on our measure of research output. The variables include real Gross Domestic Product $(G D P)$ as a measure of output, and number of research papers published by a specific country as a percentage of the total number of papers published in the world $(R)$, which in turn, measures our research output. We use natural logarithms of our two variables of interest. The GDP data comes from World Development Indicators (WDI) at constant 2005 US dollars. For the second important variable of the analysis (research output), we follow Inglesi-Lotz and Pouris (2013), Inglesi-Lotz et al., (2014, forthcoming) and Ntuli et al., (2015) in proxying research output by the share of number of publications of the country to the rest of the world. Inglesi-Lotz and Pouris (2013) argue that "the link between the economic growth and the growth in the number of publications in a country should be measured vis-à-vis the research performance of the rest of the world. It is research and innovation performance visà-vis the rest of the world that may lead to economic growth...Furthermore, such an approach 
neutralizes the fact that Thomson Reuters, in their indexing efforts, changes the set of journals indexed from time-to-time" (Inglesi-Lotz and Pouris, 2013: 132). This indicator is derived by the Institute for Scientific Information (ISI) Thomson Reuters' family of databases is employed. In the National Science Indicators database, the ISI counts articles, notes, reviews and proceeding papers, but not other types of items and journal marginalia such as editorials, letters, corrections, and abstracts (Inglesi-Lotz and Pouris 2011).

The majority of research efforts is concentrated in the developed and more industrialized countries and more specifically in the G7 countries. The G7 countries are admittedly ones with strong culture of knowledge generation and research output production due to their traditionally high growth rates and past development. So, in general, less developed countries tend to follow the trends, paths and policies of developed ones. This is demonstrated by the share of the G7 research outputs to the international outputs that was in average $73.4 \%$ in the period from 1981 to 2012. Even though this share has shown a decreasing trend $(62.1 \%$ in 2012 from $74.6 \%$ in 1981), it is clear that the great majority of countries (both developed and developing) of the rest of the world does not contribute significantly to the total number of academic papers published globally. Moreover, recently in the literature there are various studies that have used various methodological approaches to address similar theoretical research questions such as Ntuli et al. (2015) for the OECD countries; Inglesi-Lotz et al. (2015) for the BRICS; Inglesi-Lotz et al. (2014) for US; and Inglesi-Lotz and Pouris (2013) for South Africa among others. However, this study's contribution lays with the methodological approach that assumes asymmetric behavior of the studied relationship.

Tables 1 and 2 show the summary statistics of GDP and $R$ indicating real GDP and \% share of publication to the world, respectively. We find that US and Canada have the highest and lowest

Table 1. Summary statistics of real GDP (GDP)

\begin{tabular}{|l|c|c|c|c|c|c|c|}
\hline Country & Mean & \multicolumn{1}{|c|}{ Max. } & \multicolumn{1}{c|}{ Min. } & $\begin{array}{l}\text { Std. } \\
\text { Dev. }\end{array}$ & \multicolumn{1}{c|}{ Skew. } & \multicolumn{1}{c|}{ Kurt. } & J.-B. \\
\hline Canada & 27.4947 & 27.8585 & 27.0713 & 0.2514 & -0.0749 & 1.6838 & 0.3104 \\
\hline France & 28.2062 & 28.4417 & 27.8905 & 0.1823 & -0.2327 & 1.7389 & 0.2998 \\
\hline Germany & 28.0603 & 28.2496 & 27.7743 & 0.1493 & -0.5935 & 2.1098 & 0.2305 \\
\hline Italy & 28.5129 & 28.754 & 28.198 & 0.1772 & -0.4638 & 1.9337 & 0.2641 \\
\hline Japan & 28.9954 & 29.1894 & 28.5673 & 0.1870 & -1.0549 & 2.8214 & 0.0504 \\
\hline
\end{tabular}




\begin{tabular}{|l|l|l|l|l|l|l|l|}
\hline UK & 28.1900 & 28.5341 & 27.7448 & 0.2579 & -0.1760 & 1.6782 & 0.2872 \\
\hline US & 29.9129 & 30.2865 & 29.4169 & 0.2777 & -0.2520 & 1.7567 & 0.3012 \\
\hline
\end{tabular}

Note: Min.; Max., Std. Dev., Skew., Kurt., and J.-B. stands for minimum, maximum, standard deviation, skewness, kurtosis and the $p$-values for Jarque-Bera test of normality respectively.

Table 2. Summary statistics of percentage of papers published $(R)$

\begin{tabular}{|l|c|r|r|r|r|r|r|}
\hline Country & Mean & \multicolumn{1}{|c|}{ Max. } & \multicolumn{1}{c|}{ Min. } & \multicolumn{1}{c|}{$\begin{array}{l}\text { Std. } \\
\text { Dev. }\end{array}$} & \multicolumn{1}{c|}{ Skew. } & \multicolumn{1}{c|}{ Kurt. } & \multicolumn{1}{l|}{ J.-B. } \\
\hline Canada & 1.5558 & 1.6278 & 1.4709 & 0.0505 & 0.101 & 1.6202 & 0.2735 \\
\hline France & 1.7345 & 1.8724 & 1.6231 & 0.0784 & 0.2403 & 1.7875 & 0.3217 \\
\hline Germany & 2.0649 & 2.191 & 1.9878 & 0.0583 & 0.8907 & 2.4923 & 0.1015 \\
\hline Italy & 1.2446 & 1.4963 & 0.7483 & 0.2455 & -0.6643 & 1.9252 & 0.1427 \\
\hline Japan & 2.0192 & 2.2345 & 1.7485 & 0.1610 & -0.1553 & 1.613 & 0.2601 \\
\hline UK & 2.1565 & 2.2527 & 2.0461 & 0.0545 & -0.5272 & 2.6758 & 0.4444 \\
\hline US & 3.5567 & 3.6998 & 3.3145 & 0.1200 & -0.5356 & 2.0642 & 0.2595 \\
\hline \multicolumn{7}{|l|}{ Note: See Notes to Table 1. } \\
\hline
\end{tabular}

of mean real GDP respectively, while, the US and Italy have the highest and lowest shares in terms of the percentage of total research output. Based on Jarque-Bera test, we find that all of the data series are approximately normal.

\section{Empirical results}

An important issue in the analysis of panel data is to take into account a possible dependence between countries. This is because the high degree of economic and financial integration that a country can be affected by economic shocks that occurred in another. This is aside of GDP although it can indirectly affect the research output. The latter variable can show a cross-section dependence in view of the dissemination of information through the internet, the acquisition of scientific journals, conferences, etc. Therefore, the cross-section dependency can play an important role in the detection of causal links between output research and GDP. 
So, we first test for cross-sectional dependency and country-specific heterogeneity stationarity. To do this, we use the Pesaran et al. (2008)'s bias-adjusted LM test of the null hypothesis of no-cross section dependence (noted hereinafter $L M_{a d j}$ ). For testing the null of slope homogeneity, we use the $\tilde{\Delta}$ and $\tilde{\Delta}_{\text {adj }}$ tests of Pesaran and Yamagata (2008); see equations (27) and (29) in Pesaran and Yamagata (2008) for $\tilde{\Delta}$ and $\tilde{\Delta}_{a d j}$ tests, respectively. Likewise, we use the modified version of the Swamy (1970)'s test proposed by Pesaran and Yamagata (2008).

Tests for cross-sectional dependency and heterogeneity are presented in Table 3. As can be seen from results in Table 3, it is clear that the null hypothesis of no cross-sectional dependency and slope homogeneity across the countries is strongly rejected at the $1 \%$ significance level. This finding implies that a shock that occurred in one of these G7 countries seems to be transmitted to other countries. Furthermore, the rejection of slope homogeneity implies that the panel causality analysis by imposing homogeneity restriction on the variable of interest results in misleading inferences.

Table 3. Cross-sectional Dependence and Homogeneity Tests

\begin{tabular}{lc}
\hline Test & \\
\hline$L M_{a d j}$ & $14.3690^{* * * *}$ \\
$\tilde{\Delta}$ & $17.8090^{* * * *}$ \\
$\tilde{\Delta}_{a d j}$ & $18.7075^{* * * *}$ \\
Swamy Shat & $246.6701^{* * * *}$ \\
\hline
\end{tabular}

Note: $* * *$ indicates significance at the $1 \%$ level. Swamy Shat is the modified version proposed by Pesaran and Yamagata (2008) for the Swamy's test.

Also, we test for the existence of unit roots for the considered variables using the Augmented Dickey-Fuller (ADF) and the Phillips-Perron (PP) tests. The results in Table 2 indicate that the null hypothesis of a unit root cannot be rejected at the conventional 5\% level for all the series. Note that, these results were also confirmed using standard panel unit root tests 
(results for which are available upon request from the authors) as well, however, since recovering the cumulative sums for each cross-section requires us to ensure that both the series are non-stationary for each cross-section, we report the time series-based unit root tests.

Table 4: Unit roots (ADF and PP) results

\begin{tabular}{|c|c|c|c|c|c|c|c|c|c|}
\hline \multirow[t]{3}{*}{ Country } & & \multicolumn{4}{|c|}{ GDP } & \multicolumn{4}{|c|}{$\boldsymbol{R}$} \\
\hline & & \multicolumn{2}{|c|}{ Constant } & \multicolumn{2}{|c|}{ Constant and trend } & \multicolumn{2}{|c|}{ Constant } & \multicolumn{2}{|c|}{ Constant and trend } \\
\hline & & Level & 1st diff & Level & 1st diff & Level & 1st diff & Level & 1st diff \\
\hline \multirow[t]{2}{*}{ Canada } & ADF & 0.9828 & $0.0027^{\text {**** }}$ & 0.5879 & $0.0166^{* *}$ & 0.2310 & $0.0712^{*}$ & $0.0969^{*}$ & ---- \\
\hline & $\mathbf{P P}$ & 0.9765 & $0.0029^{* * * *}$ & 0.5760 & $0.0180^{* *}$ & 0.3069 & $0.0730^{*}$ & 0.5303 & 0.1377 \\
\hline \multirow[t]{2}{*}{ France } & ADF & 0.8263 & $0.0092^{\text {**** }}$ & 0.1344 & $0.0409^{* *}$ & 0.3762 & 0.2907 & 0.9902 & $0.0058^{* * * *}$ \\
\hline & $\mathbf{P P}$ & 0.8323 & $0.0167^{* *}$ & 0.6038 & $0.0741^{*}$ & 0.6605 & $0.0051^{* * * *}$ & 0.9938 & $0.0057^{* * * *}$ \\
\hline \multirow[t]{2}{*}{ Germany } & ADF & 0.8542 & $0.0003^{\text {**** }}$ & 0.5164 & $0.0029^{\text {***** }}$ & 0.6103 & $0.0096^{* * *}$ & 0.9109 & $0.0360^{* *}$ \\
\hline & PP & 0.7710 & $0.0000^{\text {***** }}$ & 0.5326 & $0.0000^{* * * *}$ & 0.6057 & $0.0088^{* * * *}$ & 0.9193 & 0.336 \\
\hline \multirow[t]{2}{*}{ Italy } & ADF & 0.3029 & $0.0046^{* * * *}$ & 0.9879 & $0.0057^{* * *}$ & 0.1488 & 0.7208 & 0.9999 & $0.0739^{*}$ \\
\hline & $\mathbf{P P}$ & 0.2915 & $0.0048^{* * *}$ & 0.9944 & $0.0018^{* * * *}$ & 0.2460 & $0.0035^{* * *}$ & 0.9999 & $0.0027^{* * *}$ \\
\hline \multirow[t]{2}{*}{ Japan } & ADF & $0.0488^{* * *}$ & ---- & 0.9358 & $0.0014^{* * * *}$ & 0.2524 & 0.6524 & 0.9999 & $0.0013^{* * * *}$ \\
\hline & PP & $0.0423^{* *}$ & ---- & 0.9404 & $0.0013^{* * *}$ & 0.6722 & $0.0349^{* *}$ & 0.9997 & $0.0014^{* * *}$ \\
\hline \multirow[t]{2}{*}{ UK } & ADF & 0.8896 & $0.0023^{\text {**** }}$ & 0.6702 & $0.0102^{\text {** }}$ & 0.9307 & $0.0002^{* * * *}$ & 0.9712 & $0.0005^{* * * *}$ \\
\hline & PP & 0.8892 & $0.0021^{\text {***** }}$ & 0.6813 & $0.0104^{\text {*** }}$ & 0.9038 & $0.0002^{* * * *}$ & 0.9740 & $0.0005^{* * * *}$ \\
\hline USA & ADF & 0.7881 & $0.0229^{* *}$ & 0.4723 & $0.0855^{*}$ & 0.9996 & $0.0003^{* * *}$ & 0.6717 & $0.0004^{* * * *}$ \\
\hline
\end{tabular}




\begin{tabular}{|l|l|l|l|l|l|l|l|l|l|}
\hline & PP & 0.8501 & $0.0201^{* *}$ & 0.7212 & $0.0765^{*}$ & 0.9997 & $0.0003^{* * *}$ & 0.6737 & $0.0004^{* * *}$ \\
\hline
\end{tabular}

Notes: Figures denote $p$-values. ${ }^{* * * * *},{ }^{* *}$ and ${ }^{*}$ indicate the rejection of the null hypothesis at the $1 \%, 5 \%$ and $10 \%$ levels, respectively.

The causality results are reported in Table 5. The non-asymmetric causality results provide that the null hypothesis that the research is not causing GDP cannot be rejected except for the UK at the $5 \%$ significance level. The estimated causal parameter is 0.1737 , which mean a $1 \%$ augmentation in publications will cause $0.1737 \%$ augmentation in the UK growth. On the other hand, the asymmetric causality results reveal that the null hypothesis of positive shock in research not causing similar shocks in GDP cannot be rejected for all G7 countries. However, the null hypothesis that negative research shocks do not cause negative shocks in GDP can be rejected for Italy, Japan, and the US. Results provide that $1 \%$ permanent negative research shock will cause a $0.3404 \%, 0.1349 \%$ and $0.0935 \%$ reduction in GDP for Italy, Japan and US, respectively. These results constitute the other side of the coin and confirm the endogenous growth theory through a dependence of GDP on research output. However, beyond a certain threshold, an increase in research output cannot generate an increase in GDP.

Table 5. The Asymmetric Panel Causality Test Results

\begin{tabular}{|c|c|c|c|}
\hline NULL HYOTHESIS & Test Value & P-values & Causal Parameter \\
\hline Canada & & & \\
\hline $\boldsymbol{R} \neq>G D P$ & 1.578744 & 0.2089 & \\
\hline $\boldsymbol{R}^{+} \neq>\boldsymbol{G D P} \boldsymbol{P}^{+}$ & 0.178634 & 0.6725 & \\
\hline $\boldsymbol{R}^{-} \neq>\boldsymbol{G D P}$ & & & \\
\hline France & 0.759305 & 0.3835 & \\
\hline $\boldsymbol{R}^{-} \neq$GDP & 0.000188 & 0.9891 & \\
\hline $\boldsymbol{R}^{+} \neq>\boldsymbol{G D P} \boldsymbol{P}^{+}$ & 0.006204 & 0.9372 & \\
\hline $\boldsymbol{R}^{-} \neq>\boldsymbol{G D P} \boldsymbol{P}^{-}$ & 1.108939 & 0.2923 & \\
& & & \\
\hline
\end{tabular}




\begin{tabular}{|c|c|c|c|}
\hline Germany & & & \\
\hline $\boldsymbol{R} \neq>G D P$ & 0.034461 & 0.8527 & \\
\hline$R^{+} \neq>G D P^{+}$ & 0.125916 & 0.7227 & \\
\hline$R^{-} \neq>G D P^{-}$ & 2.654896 & 0.1032 & \\
\hline \multicolumn{4}{|l|}{ Italy } \\
\hline $\boldsymbol{R} \neq>G D P$ & 0.495892 & 0.4813 & \\
\hline$R^{+} \neq>G D P^{+}$ & 0.542448 & 0.4614 & \\
\hline$R^{-} \neq>G D P^{-}$ & 16.09491 & 0.0001 & 0.3404 \\
\hline \multicolumn{4}{|l|}{ Japan } \\
\hline $\boldsymbol{R} \neq>G D P$ & 1.287603 & 0.2565 & \\
\hline$R^{+} \neq>G D P^{+}$ & 1.824621 & 0.1768 & \\
\hline$R^{-} \neq>G D P^{-}$ & 7.038391 & 0.0080 & 0.1349 \\
\hline \multicolumn{4}{|l|}{ UK } \\
\hline $\boldsymbol{R} \neq>G D P$ & 3.992459 & 0.0457 & 0.1737 \\
\hline$R^{+} \neq>G D P^{+}$ & 0.468396 & 0.4937 & \\
\hline$R^{-} \neq>G D P^{-}$ & 1.818385 & 0.1775 & \\
\hline \multicolumn{4}{|l|}{ US } \\
\hline $\boldsymbol{R} \neq>G D P$ & 0.908474 & 0.3405 & \\
\hline$R^{+} \neq>G D P^{+}$ & 1.089122 & 0.2967 & \\
\hline$R^{-} \neq>G D P^{-}$ & 4.060224 & 0.0439 & 0.0935 \\
\hline
\end{tabular}

Notes:

1. $R$ represents research and $G D P$ represents gross domestic product. The vector $\left(R^{+}, G D P^{+}\right)$signifies the cumulative positive shocks and $\left(R^{-}, G D P^{-}\right)$represents the cumulative negative shocks. 
2. The Hatemi-J (2011) asymmetric panel causality test is used. The statistical software component produced by Hatemi-J (2014) is utilized to transform the underlying data into cumulative positive and negative parts. The VAR-SUR model is estimated by using EViews 7.

\section{Conclusion and policy implications}

There is a general belief stating that the results of scientific research will lead to industrial development. This belief was all the more confirmed since several longitudinal studies have shown that GDP and the number of published papers are in parallel. However, several authors working on this topic have not found that the output of research can generate an economic development. In a more precise way, their results were varied and depend on, inter alia, the studied cases, the nature of the indicators adopted for the research output and statistical methods. In this paper, we investigated the causal relationship between economic growth and research output using an annual data covering the period from 1981 to 2012 for the G7 countries. Specifically, the studied variables included real GDP and research papers published as a percentage of total numbers of papers published in the world economy. To have some practical insights about this relationship, we used the asymmetric panel causality test of Hatemi-J (2011, 2014). Allowing for potential asymmetry is convenient in our analysis since there are several empirical studies that have shown that GDP can incorporate an asymmetric component; see, inter alia, Verbrugge (1997) and Belair-Franch and Contreras (2002). Obviously, asymmetric changes in GDP may have direct effects on research output. An advantage of panel data analysis is that it results in increased degrees of freedom especially when the time series dimension is rather short as it is the case in this study. We found that there are causal relationships running from output research to GDP for only the UK, the Japan, Italy, and the US. For the former, causality is defined without cumulative shocks. However, for the last three countries, causality was running from negative cumulative output research shocks to negative cumulative GDP shocks. So there are no causality relationships for Canada, France and Germany. Therefore, if the interest is not paid for asymmetric causal relationships, our results show that there is no causality running from research output to GDP for all the countries studied except for the UK.

The absence of a relationship between academic research output and economic growth could be attributed to the type of research conducted, the specific areas and research-result transmission, either as knowledge or skills, to the rest of the economy. This problem was highlighted in some 
ways, by Vinkler (2008), who mentioned that grants for scientific research offered by countries may depend primarily on potentials, not on needs. Rich countries are able to spend more without addressing the needs of a real economic recovery (Nelson and Romer (1996)). For that reason, it is recommended that universities must provide commendable efforts to revitalize the relationship with growth by aligning their research with current industry needs. It goes without saying that education is indispensable to achieve this goal. At this level, it is hoped that policymakers need to continuously adjust their programs to the real needs of their economies. A desired result of this adjustment is the emergence of a breeding ground of graduates able to extend their knowledge beyond the existing limits.

Adding to the explanation for the absence of a relationship between research output and economic growth is the lack of appropriate links between the "knowledge" sector and the "productive" industrial sector. The policy makers can change this situation by creating, promoting and supporting such channels not necessarily only by monetary funding programmes but also by facilitating efforts between academic and research institutions and the absorption of their outputs in the economic production. Working towards making sure that in the future research outputs and hence knowledge stock of the country has an effect on economic growth is beneficial for policy makers as a new tool for macroeconomic policies towards growth and development can be suggested.

\section{References}

Belaire-Franch, J. and Contreras, D. 2002. A Pearson's test for symmetry with an application to the Spanish business. Spanish Economic Review 4: 221-238

De Moya-Anegón, F. and Herrero-Solana, V. 1999. Science in America Latina: A comparison of bibliometric and scientific-technical indicators. Scientometrics 46:299-320.

Fedderke, J. W., \& Schirmer, S. 2006. The R\&D performance of the South African manufacturing sector, 19701983. Economic Change, 39, 125-151.

Hatemi-J, A. 2011. Asymmetric Panel Causality tests with an application to the impact of fiscal policy on economic performance in Scandinavia. MPRA Paper No 55527.

Hatemi-J A. 2014 Asymmetric generalized impulse responses with an application in finance, Economic Modelling, vol. $36,18-22$. 
Inglesi-Lotz, R., and Pouris, A., 2013. The influence of scientific research output of academics on economic growth in South Africa: an autoregressive distributed lag (ARDL) application. Scientometrics, 95, 131-141.

Inglesi-Lotz, R., Balcilar, M., Gupta, R., 2014. Time-Varying Causality between Research Output and Economic Growth in US. Scientometrics, 100: 203-216

Inglesi-Lotz, R., Chang, T., Gupta, R. 2015. "Causality between research output and economic growth in BRICS”. Quality and Quantity, 49(1): 167-176.

Kealey, T. 1996. The economic laws of scientific research. New York: St. Martin's Press.

King, D. A. 2004. The scientific impact of nations. What different countries get for their research spending. Nature, 430, 311-316.

Lee, L-C., Lin, P-H., Chuang, Y-W. and Lee, Y-Y. 2011. Research output and economic productivity: a Granger causality test. Scientometrics 89:465-478.

Lucas, R.E. 1988. On the mechanics of economic development. Journal of Monetary Economics 22:3-42.

Nelson, R. R. and Romer, P. M. 1996. Science, economic growth and public policy. Challenge 39(2) : 9-21.

Ntuli , H., Inglesi-Lotz, R., Chang, T., Pouris, A., (2015). Does research output cause economic growth or vice versa? Evidence from 34 OECD countries. Journal of the Association for Information Science and Technology 66(8): 1709-1716.

Pesaran, M.H., Yamagata, T. 2008. Testing slope homogeneity in large panels. Journal of Econometrics 142:50-93.

Pesaran, M.H., Ullah, A. and Yamagata, T. 2008. A bias-adjusted LM test of error cross-section independence. Econometrics Journal 11:105-127.

Pouris, A. and Pouris, A. 2009. The state of science and technology in Africa (2000-2004): A scientometric assessment. International Journal of Scientometrics 79:297-309.

Price, D.S. 1978. Toward a model for science indicators. In Elkana, Y., Lederber, G.J., Merton, R.K., Thackray, A., and Zuckerman, H. (Eds). Toward a metric of science: the advent of science indicators. New York: John Wiley \& Sons.

Romer, P.M. 1986. Increasing returns and long-run growth. Journal of Political Economy 94:1002-1037.

Schubert, A. and Telcs, A. 1986. Publication potential- An indicator of scientific strength for cross-national comparisons. Scientometrics 9:231-238. 
Shelton, R.D. \& Leydesdorff, L. 2011. Bibliometric Evidence for Funding Trade-Offs in National Funding Strategies, 13th International Conference on Scientometrics and Informetrics, Durban, July. 2011. Available at http://itri2.org/s/

Swamy, P.A.V.B. 1970. Efficient inference in a random coefficient regression model. Econometrica 38:311-323.

Verbrugge, R.J. 1997. Investigating cyclical asymmetries. Studies in Non-linear Dynamics and Econometrics 2: 110

Vinkler, P. 2008. Correlation between the structure of scientific research, scientometric indicators and GDP in EU and non-EU countries. Scientometrics, 74, 237-254. 